\title{
Application of Synchrotron Radiation X-ray Diffraction (SR-XRD) and Electron Probe Microanalysis to Understanding Gold Mineralization at the Vertigo Target, White Gold District, West-Central Yukon Territory, Canada
}

\author{
James Alexander, Neil Banerjee and Lisa Van Loon
}

Western University, London, Ontario, Canada

Introduction: The Vertigo target is a gold mineralized zone located $70 \mathrm{~km}$ south of Dawson City in the Yukon's White Gold District of the Dawson Range Mineral Belt of the west-central Yukon Territory's Yukon-Tanana terrane (YTT). Au mineralization at the Vertigo target is hosted in a series of moderateto-high-angle, E-SE striking, SSW dipping polyphase auriferous quartz veins, fracture sets and breccias. $\mathrm{Au}$ is associated with pyrite+/-arsenopyrite+/-galena, occurring in magnetite-destructive quartz-sericitechlorite+/-carbonate alteration zones, and preferentially develops in felsic-to-intermediate host rock lithologies. A petrographic and geochemical study is in progress to understand the controls on $\mathrm{Au}$ mineralization. Petrography used in conjunction with electron probe microanalysis (EPMA) and synchrotron radiation X-ray diffraction (SR-XRD) analysis is being used to assess the characteristic signatures of $\mathrm{Au}$ mineralization to help define the genesis of ore formation at the Vertigo discovery. Observed geochemical associations with Au at the Vertigo target are unlike any other prospects discovered in the White Gold District to date.

Synchrotron micro-X-ray Diffraction (SR-XRD) is a time-proven analytical tool used to discriminate the mineralogical assemblage of geologic materials [1]. The high flux generated from the synchrotron source allows for the application of high quality, high resolution and high throughput analyses of hundreds to even thousands of samples [1]. The collection of such statistically significant data demonstrates the capacity of SR-XRD to effectively integrate geochemical information within its mineralogical context at a rapid throughput [1]. The application of SR-XRD, used with coincident EPMA provides an innovative method for sample characterization novel to the minerals industry.

Experimental: Au mineralized drill core samples were selected and prepared as polished thin sections. Thin sections were analyzed under transmitted and reflected light using a Nikon Eclipse LV100POL microscope at the Earth and Planetary Materials Analysis facility at Western University. Regions of interest chosen were identified by petrographic analysis for further electron dispersive spectroscopic (EDS) electron probe micro-analysis (EPMA) to discern elemental relationships and confirm mineralogical interpretations. Wavelength dispersive spectroscopy (WDS) was then used to produce elemental maps for $\mathrm{S}, \mathrm{Fe}, \mathrm{Cu}, \mathrm{Zn}, \mathrm{As}, \mathrm{Ag}$, Te, $\mathrm{Au}, \mathrm{Pb}$, Bi on specific regions of interest identified during EDS analysis. EDS and WDS analyses were completed using a JEOL JXA-8530F Hyperprobe field emission source electron microprobe at the Earth and Planetary Materials Analysis facility at Western University.

Crushed samples corresponding to each thin section were selected for SR-XRD analysis. SR-XRD patterns were collected on powders of the same samples remotely using the Canadian Macromolecular Crystallography Facility (CMCF) beamline 08BM-1 at the Canadian Light Source (CLS) using established setup parameters for geologic materials [1]. The results were used to identify key mineral phases and support petrographic interpretations. SR-XRD analyses were collected at a resolution of 1.29 $\AA$, exposure of 5 seconds, for 24 scans, using an incident energy of $18 \mathrm{keV}$, and beam aperture of $150 \mu \mathrm{m}$. 
Results and Discussion: Petrography supplemented by EDS-EPMA was used to determine textural relationships and Au-sulphide associations. Coarse visible Au occurs along fractures and in quartz veins, having sulphide associations with semi-massive-subhedral arsenopyrite, anhedral-subhedral galena and subhedral pyrite. Free $\mathrm{Au}$ is observed at relatively lower grades in fractures cross-cutting arsenopyritebearing quartz veins (Au-As), and at moderate grades in fractures cross-cutting galena-rich quartz veins $(\mathrm{Au}-\mathrm{Pb})$. High-grade $\mathrm{Au}$ mineralized structures are typically associated with upper oxidized zones containing As-Ag-Te-Au-Pb-Bi, where sulphide associations are indistinguishable due to intense oxidation. A WDS map created for a high-grade sample was focused on a Au-bearing grain with the same mineralogical make up as the mineral beudantite $\left(\mathrm{PbFe}_{3}\left(\mathrm{AsO}_{4}\right)\left(\mathrm{SO}_{4}\right)(\mathrm{OH}) 6\right)$ (Figure 1). Complementary quantitative phase identification of the SR-XRD data for the high-grade sample interprets the best fit diffractogram peaks for the mineral beudantite, however further analysis is needed to verify this interpretation (Figure 2).

Petrography and EPMA used in conjunction with SR-XRD phase identification are proving as effective tools in assessing the characteristic signatures of Au mineralization and genesis of ore formation at the Vertigo discovery. Beudantite is a secondary mineral that occurs in the oxidized zones of polymetallic deposits [2]. Identifying beudantite as being part of this mineralizing system helps explain some of the discrepant elemental relationships observed and provides a preliminary account for the conspicuous $\mathrm{Au}$ grade enrichment in the oxidized zones of the Vertigo showing. Mineralogy, alteration and oxidation appear to play a key role in governing Au grades at Vertigo. The Au grade distribution at Vertigo determined by applying SR-XRD across the showing will have implications for assessing the economic feasibility and metallurgical recovery in developing this target into a deposit.

Acknowledgements: Research described in this paper was performed at the Canadian Light Source (CLS). The CLS is supported by the CFI, NSERC, the Univ. of Saskatchewan, the Government of Saskatchewan, Western Economic Diversification Canada, the NRC, and the CIHR. The authors acknowledge funding from NSERC and White Gold Corp. We thank M. Fodje and S. Labiuk for support in conducting the experiments. 

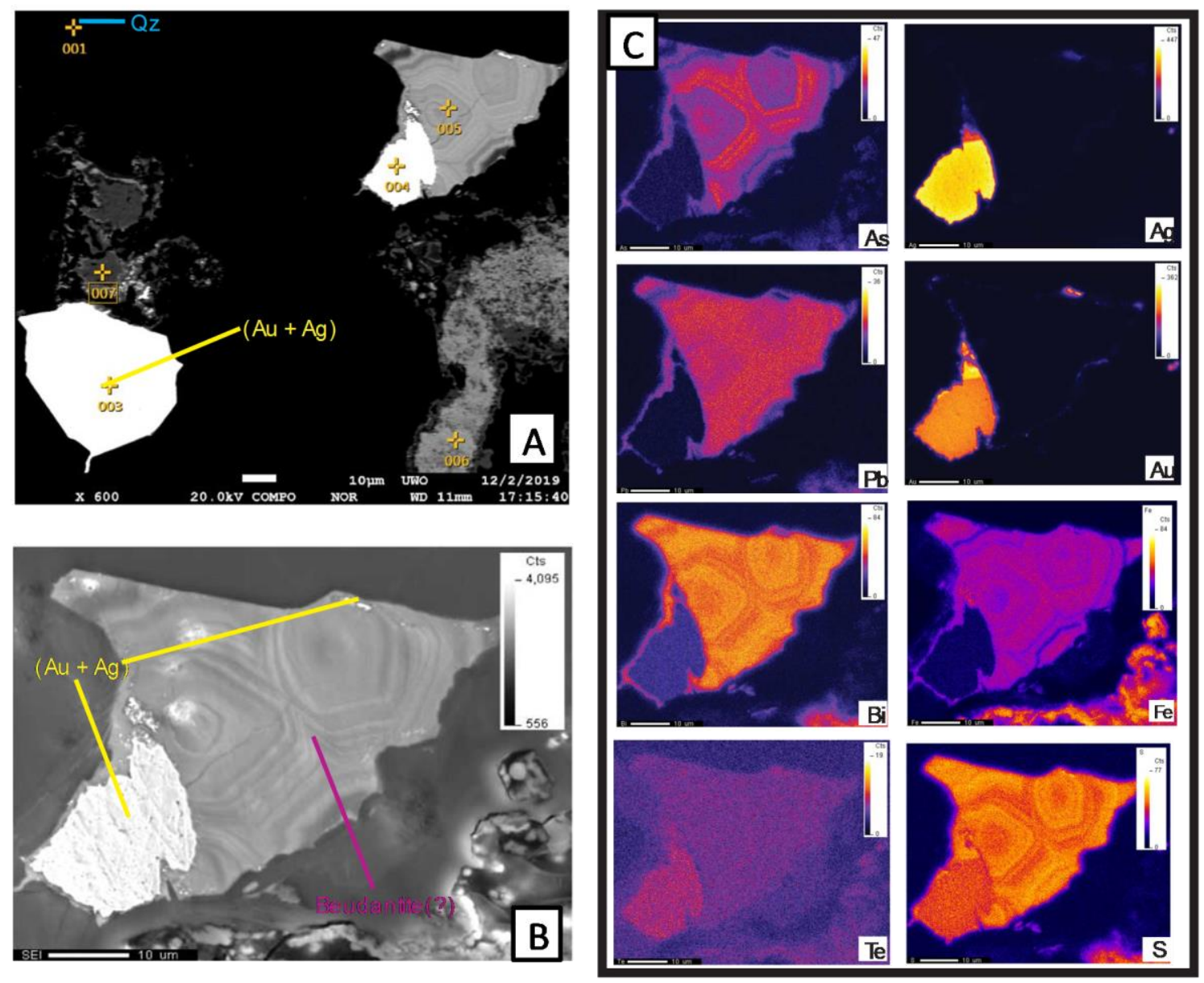

Figure 1. (A) Back-scattered electron image (BSE) of Au-Ag in quartz vein with oxides and possible beudantite. (B) Secondary-electron image (SEI) of zone mapped with WDS where Au-Ag complex appears confined by possible beudantite. (C) WDS maps showing element concentrations in grain of interest. 


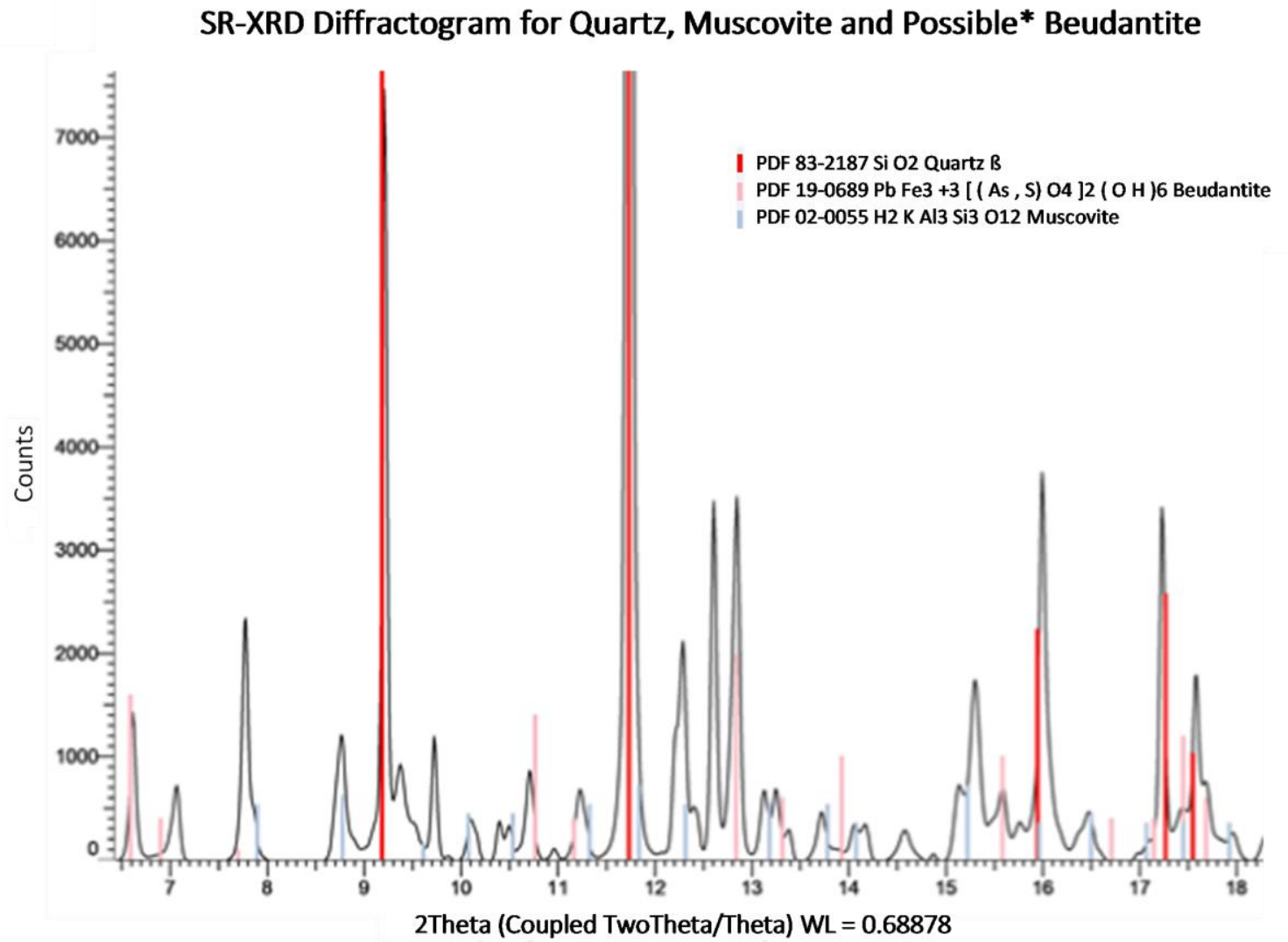

Figure 2. SR-XRD diffractogram displaying peak fits for quartz (red), muscovite (light blue) and possible* beudantite (pink).

\section{References}

[1] Banerjee, N., Van Loon, L., Botor, R., \& Flynn, T. (2018). Automated Geochemical and Mineralogical Synchrotron Characterization of Bulk Geological Materials: An Innovation for the Minerals Industry. Microscopy and Microanalysis, 24(S2), 518-519.

[2] Hudson Institute of Mineralogy. https://www.mindat.org/min-652.html. 2020. 